BULLETIN Bulletin hispanique

HISPANIQUE Université Michel de Montaigne Bordeaux

109-2 | 2007

La formation du Parnasse espagnol $\mathrm{XV}^{\mathrm{e}}-\mathrm{XVIII}{ }^{\mathrm{e}}$ siècle

\title{
Desterradas del parnaso
}

Examen de un monte que solo admitió musas

\section{Nieves Baranda}

\section{(2) OpenEdition}

\section{Journals}

Edición electrónica

URL: http://journals.openedition.org/bulletinhispanique/236

DOI: 10.4000/bulletinhispanique.236

ISSN: 1775-3821

Editor

Presses universitaires de Bordeaux

\section{Edición impresa}

Fecha de publicación: 1 diciembre 2007

Paginación: 421-447

ISBN: 978-2-85276-096-7

ISSN: 0007-4640

Referencia electrónica

Nieves Baranda, «Desterradas del parnaso », Bulletin hispanique [En línea], 109-2 | 2007, Publicado el

01 diciembre 2010, consultado el 01 mayo 2019. URL : http://journals.openedition.org/

bulletinhispanique/236 ; DOI : 10.4000/bulletinhispanique.236 


\title{
Desterradas del parnaso. Examen de un monte que solo admitió musas ${ }^{1}$
}

\author{
Nieves Baranda \\ UNED - Madrid
}

Examen de diverses euvres littéraires et critiques qui peuvent être considérées comme des éléments de constitution du canon Littéraire aux XVI et XVII siècles. L'objectif est d'établir la place faite aux auteures, de relever les noms mentionnés et d'identifier celles qui éventuellement sont parvenues à faire partie du canon.

Revisión de diversas obras literarias y criticas que podrian ser consideradas elementos de conformación del canon Literario en los siglos XVI y XVII, con el fin de establecer qué lugar asignaron a las escritoras, cuáles mencionan y quiénes llegaron a formar parte de ese canon, si es que alguna lo logró.

A review of different literary and critical works which during $16^{\text {th }}$ and $17^{\text {th }}$ centuries can be said to help conform the Literary canon in order to determine which place they assigned to women writers, which women were mentioned, and which ones if any at all reached canonicity.

Mots-clés : Auteures espagnoles - XVI-XVII ${ }^{\mathrm{e}}$ siècle - Canon - Galeries de femmes - Compilations poétiques - Critiques d'histoire littéraire.

1. Este trabajo se inscribe en el Proyecto de Investigación «Bibliografía de escritoras españolas (Edad Media-siglo XVIII). II», (HUM 2006-03215) del Ministerio de Educación, Ciencia y Tecnología. Sus planteamientos se consideran complementarios de los que traza también en este volumen el trabajo de M. ${ }^{a}$ Carmen Marín Pina.

$B H i$, Tome 109, nº 2 - décembre 2007 - p. 421 à 447. 
C1 parnaso es ajeno a las mujeres. Si llegar a su cumbre es difícil para los hombres, lo es aún más para las féminas. Basta revisar la lista de escritoras del Siglo de Oro que nos ofrecen las historias de la literatura a lo largo del siglo XX (época de supuesta vocación igualitaria en los asuntos de género) para observar la escasez de sus nombres y la falta de unanimidad sobre la selección de los mismos, como concluyó M. ${ }^{a}$ Carmen Marín Pina en el último congreso de la $\mathrm{AISO}^{2}$. A pesar de que tradicionalmente se ha sostenido que la selección del canon es un proceso «natural» que criba las obras por su calidad -estética o de otro tipo-, la realidad es que en su conformación operan muchos factores y que los juicios estéticos nunca tendrán valor si no se realizan en ciertos contextos institucionales y se reiteran en el tiempo para sucesivas generaciones de lectores. Porque el canon, el parnaso como la cima de sus elites culturales, recordémoslo una vez más, es una cuestión de poder, del poder que impone en cada generación a unos autores sobre otros y que deja a las mujeres en los márgenes, también en aplicación de esa misma falta de poder y representatividad pública que tienen en la sociedad.

Sin embargo, el resultado de esta criba social no es una ausencia absoluta, sino una selección de nombres, minoritaria, que sirve para dar credibilidad al sistema más que para ponerlo en entredicho. Por ejemplo, es frecuente cuando se habla del humanismo, el renacimiento y la promoción de la mujer, referirse a las puellae doctae citadas por Lucio Marineo Sículo para hablar sobre sus nombres de toda una generación de mujeres con profundos conocimientos de la cultura clásica, que proliferaron sobre todo a la sombra de Isabel la Católica; también se alude a varias mujeres escritoras que formaron parte del grupo poético antequerano-granadino, con Cristobalina Fernández de Alarcón como figura más visible. Sin embargo, calibrar el peso específico literario de esas mujeres con frecuencia mencionadas produce desconcierto, ya que detrás de esas menciones eruditas apenas hay algún escrito que sustancie la aparente fama ${ }^{3}$. Bien al contrario, cuando se procede

2. M. ${ }^{a}$ Carmen Marín Pina y N. Baranda, "Bibliografia de escritoras españolas (Edad Media-siglo XVIII). Una base de datos", en Edad de Oro cantabrigense. Actas del VII Congreso de la Asociación internacional Siglo de Oro (AISO) (Robinson College, Cambridge, 18-22 julio, 2005), Madrid: Iberoamericana Vervuert, 2006, pp. 425-436; otra perspectiva sobre el tema en el monográfico de la revista Voz y Letra, XVI/2 (2006).

3. Sobre este tema vid. N. Baranda, «Mujeres y cultura letrada en la época de Isabel la Católica», Ínsula, 691-692 (2004), pp. 27-28; e infra n. 12; y Carmen Peraita, «Sapientia and Knowledge in the Construction of the Renaissance docta foemina: Vive's De institutione foeminae christianae», en Acta conventus neo-latini abulensis. Proceedings of the Tenth International Congress of Neo-Latin Studies, ed. de Rhoda Schur, Tempe (Arizona): Arizona Center for Medieval and Renaissance Studies, 2000, pp. 499-506. 
en sentido inverso partiendo de los Apuntes de Serrano y Sanz ${ }^{4}$ para llegar a seleccionar escritoras relevantes del período que nos ocupa, destacan entre las poetas las hermanas Cecilia y María Sobrino (más conocidas como Cecilia del Nacimiento y María de San Alberto), Leonor de la Cueva, Catalina Clara Ramírez de Guzmán o Marcia Belisarda; entre las prosistas Valentina Pinelo o la Condesa de Aranda; entre las dramaturgas Ángela de Acevedo o Ana Caro Mallén. Ninguna de ellas suele mencionarse entre las escritoras, ¿cómo se invierte de forma tan flagrante el principio de Arquímedes?, es decir, ¿por qué no hay correspondencia entre estas escritoras de las que tenemos una obra de cierta extensión y el brillo de las citas de autoridad?

Resulta evidente que entre ambos extremos, la realidad invisible y la visibilidad irreal, existe un proceso de filtro de la información que es el que establece la sociedad literaria, es decir, esa «institución, regulada por un código en buena parte tácito e informal de preceptos y recomendaciones, y dotada de instancias de autorización y censura específicas», en palabras de Mercedes Blanco ${ }^{5}$. Efectivamente, nada se descubre al afirmar que dado que la obra literaria solo existe dentro de esa sociedad, son sus mecanismos de control los que actúan sobre ella concretados en las llamadas instancias de autorización, imprescindibles para que podamos hablar de campo literario. Esos agentes de la autoridad, por más que varíen en cada generación y en cada época, tienen en gran medida a los propios escritores como su fundamento, ya que son los más interesados y primeros en ejercer esta función selectiva, más aún en lo que se refiere al Siglo de Oro, cuando todavía no se vislumbra la existencia de las complejas y sucesivas instancias normativas que casi coordinadamente actúan en la actualidad (textos escolares, críticos, autores, prensa, sistema editorial, etc.). Tal como sostiene Jose Adriano de Freitas Carvalho en este mismo volumen, el parnaso siempre son juicios de poetas sobre otros poetas. Y entonces - como ahora- las bases de esa normatividad y su expresión son principalmente el metadiscurso, la intertextualidad y la selección de «modelos», bien sea en el espacio físico (academias) o simbólico (parnasos, antologías y compendios varios), que se ofrecen como vías para calibrar las posiciones relativas dentro del sistema ${ }^{6}$.

4. M. Serrano y Sanz, Apuntes para una biblioteca de escritoras españolas desde el año 1401 al 1833, Madrid: Biblioteca Nacional..., 1903-1905, 2 vols, con reimp. en BAE, ts. CCLXVIIICCLXXI.

5. M. Blanco, "Poéticas, retóricas y estudio crítico de la literatura», Penser la littérature espagnole. Bulletin Hispanique, 1 (2004), pp. 213-233, p. 223.

6. Pierre Bourdieu, en quien se apoyan teóricamente estas sencillas líneas, aplica sus tesis al arte pos-industrial, sin embargo, sus postulados pueden ser fructíferamente empleados con los debidos matices a épocas anteriores, según han demostrado M. Blanco, art. cit., o 
Perseguir en estos discursos y selecciones a las escritoras es casi lo mismo que buscar una aguja en un pajar, ya que en su mayor parte o las desconocen o las ignoran cuando de confeccionar el parnaso se trata, tal como demuestra la larga nómina que establece Pedro Ruiz, por ejemplo ${ }^{7}$. Ciertamente no es igual en todas esas instancias ni en todo el período. El espacio donde más clamorosa es esta ausencia son las academias ${ }^{8}$, posiblemente porque esos lugares de sociabilidad que se presentan como "escuelas del mundo" funcionan dentro de la sociedad literaria como colegio cultural invisible para la administración del poder simbólico inherente a los modelos literarios. No podemos afirmar que no participara ninguna mujer, porque unas pocas fuentes hablan en ocasiones de espectadoras, otras nos relatan la presencia de participantes anónimas y algunas afirman que, por ejemplo, María de Zayas fue aplaudida en las academias de Madrid (y si ella tomó parte, por qué no otras). No obstante, las actas o testimonios académicos conservados, espejo selecto de estas sociedades, no revelan ningún rastro femenino y al reflexionar sobre los temas poéticos preferidos entre sus miembros se puede entender que fuera así, ya que el tema amoroso y sus circunstancias, tan del gusto de estas reuniones, solo tiene sentido planteado desde una óptica masculina, puesto que el objeto en torno al que gira toda la tópica (ya sea de simple expresión, narración, censura o sátira) es femenino ${ }^{9}$.

Fuera de las justas y certámenes donde se compite por el premio y donde no se puede hablar de una auténtica selección preliminar ${ }^{10}$, las antologías

J. Vélez-Sainz, El Parnaso español: canon, mecenazgo y propaganda en la poesía del Siglo de Oro, Madrid: Visor Libros, 2006, etc.

7. Además del trabajo publicado en este volumen vid. «Espejos poéticos y fama literaria: las epístolas en verso del siglo XVI», Penser la littérature espagnole. Bulletin Hispanique, 1 (2004), pp. 45-80.

8. Jean-Pierre Etienvre, "Visages et profils féminins dans les Academias littéraires du XVII ${ }^{e}$ siècle», en A. Redondo, ed., Images de la fermme en Espagne aux XVI et XVII siècles. Des traditions aux renouvellements et à l'émergence d'images nouvelles, París: Presses de la Sorbonne Nouvelle, 1994, pp. 351-364.

9. Se podría confrontar la situación española con otros países, vid. para Portugal, donde no hay ninguna mujer, João Palma-Ferreira, Academias literárias dos séculos XVII e XVIII, Lisboa: Biblioteca Nacional, 1982, pp. 19-44; un caso bien distinto lo presenta Italia, según expone Elisabetta Graziosi, "Aracadia femminile: presenze e modelli», Filologia e Critica, XVII (1992), pp. 321-358. En cuanto a los temas, cabe recordar la cita de Melo que recoge J. Adriano de Freitas Carvalho afirmando que los religiosos no debían tratar estos temas y por lo tanto no podían ocupar el parnaso; ¡de las damas ya ni qué decir tiene!

10. Sobre este tema vid. N. Baranda, «Las mujeres en las justas poéticas madrileñas del siglo XVII», Hommage à Jacqueline Ferreras, ed. de Thomas Gomez, París: Centre de Recherches Ibériques et Ibéro-Americaines de l'Université Paris X, 2003, pp. 19-41; luego recogido en su libro Cortejo a lo prohibido. Lectoras y escritoras en la España Moderna, Madrid: Arco Libros, 2005. 
poéticas impresas que incluyen escritoras como parte de su propuesta normativa son pocas. Se podría empezar por el Cancionero general, donde solo ocupa un lugar de cierto relieve Florencia Pinar, si bien su presencia pasó totalmente desapercibida para la posteridad, puesto que ni siquiera un compilador con pretensiones de exhaustividad como Nicolás Antonio la menciona. Bien es cierto que la compilación de Hernando del Castillo representa los gustos creativos de una época que entre los poetas de la escuela petrarquista se considera obsoleta y de la que apenas se rescatan Mena o Santillana como auctoritates, de ahí que no sea ni mucho menos la única ausencia cancioneril en el canon establecido en los siglos XVI y XVII ${ }^{11}$.

Los cancioneros manuscritos del siglo XVI apenas si registran dos o tres nombres de mujeres y entre ellos destaca Isabel de Vega, por ser autora de varios poemas que incluso aparecen en más de una fuente, circunstancia verdaderamente excepcional que la diferencia de todas las demás. No obstante, estas compilaciones reflejan el gusto particular de su recopilador y aunque la copia reiterada de una composición en muchos testimonios nos habla de su difusión, el conjunto de estos cancioneros solo a título de gusto privado pretendió ejercer funciones de selección canónica, lo que les resta valor para este examen. Resulta imprescindible, por el contrario, acudir a la que desde su título se postula como un espejo poético: las Flores de poetas ilustres (1605) de Pedro Espinosa. En esta selección impresa se codean con Góngora, Quevedo o Lope de Vega, tres poetas antequeranas: Cristobalina Fernández de Alarcón y las hermanas Luciana e Hipólita de Narváez ${ }^{12}$ y para ellas significará el paso a la posteridad en calidad de poetas, pues su nombre será citado una y otra vez por la crítica pasada y actual como ejemplo de la existencia de mujeres cultivadoras de poesía en el Siglo de Oro, tal como se afirmaba al principio. Ahora bien, contemplar a estas antequeranas sobre el trasfondo de lo que es todo el ramo de flores nos muestra que su número apenas es testimonial (tres poemas de Hipólita de Narváez, dos de

11. No incluyo en estas menciones el Cancionero general de obras nuevas, sobre el que se puede consultar en este mismo volumen el trabajo de Víctor Infantes; para la selección que el canon del Siglo de Oro hace de los poetas medievales, vid. en este volumen los trabajos de G. Serés y A. Estévez.

12. Estudiadas en detalle por Belén Molina Huete, Una poetisa perdida del Siglo de Oro español: Cristobalina Fernández de Alarcón y Voces femeninas en el petrarquismo del Siglo de Oro: D. a Hipólita y D. a Luciana de Narváez, Madrid: Asociación de Eslavistas Españoles, 2001, para ambas; agradezco a la autora que me enviara copia de estas publicaciones imposibles de obtener. Todas estas autoras fueron luego citadas en la Historia de Antequera del P. Cabrera, según recuerda B. Molina, Una poetisa.., pp. 26-27; y Cristobalina elogiada en las Rimas varias del licenciado D. Jerónimo de Porras, natural de Antequera, Antequera: Juan Bautista Moreina, 1639, ff. 74v-75r, donde se la llama Safo espańola. 
Cristobalina, uno de Luciana) y que si para los poetas se acudió a muertos y vivos, a andaluces, castellanos, aragoneses y hasta portugueses, para las mujeres poetas (poetisas) solo la vecindad sirvió de recomendación, pues ninguna de las que por entonces escribían en otros lugares llegó a tener cabida entre los versos preferidos por Espinosa. Son criterios de selección que veremos repetidos otras veces.

En todo caso parece necesario subrayar la trascendencia o visibilidad que dicha compilación tuvo en contraste con otras de carácter conmemorativo, donde hay una pequeña presencia femenina que pasa totalmente desapercibida. Cabe recordar a Leonor de la Cueva y Silva, cuyo soneto dedicado a la muerte de la reina María Luisa de Borbón ( «La flor de Francia, lis que a nuestra España»), apareció en al menos cuatro impresos distintos ${ }^{13}$. Otro suyo, a la muerte de D. a Isabel de Borbón («Este grandioso túmulo erigido") se incluyó en la Pompa funeral, honras y exequias en la muerte de ...doña Isabel de Borbón...que se celebraron en el real convento de San Gerónimo de la villa de Madrid ${ }^{14}$, donde aparece asimismo el soneto de María Nieto de Aragón, "Cede al sueño fatal la que divina». Éste se editó otras dos veces en obras conmemorativas a la muerte de Isabel de Borbón ${ }^{15}$ y fue elogiado por Gracián en su Agudeza y arte de ingenio. Asimismo hay dos poemas suyos en Epitome de la admirable y exemplar vida de D. Fernando de Córdoba Bocanegra, de Rodrigo Méndez Silva ${ }^{16}$; y otros dos en una compilación manuscrita hecha a la muerte de Manuel Cortizos de Villasante ${ }^{17}$. Estas

13. Todos ellos, por cierto, sin año, aunque el deceso ocurrió en 1689: en J. Lomas Cantoral, Cantos fúnebres de los cisnes del Manzanares a la temprana muerte de su mayor reyna doña María Luisa de Borbón..., s.l., s.i., s.a., 98 hs. fol. 98v.; Gaspar Agustín de Lara, Numeroso desengaño de la vida, breve diseño de la muerte de la Reyna N.S. D. a Luisa María de Borbón..., (12 hs.); Antonio Bartolomé de Benavides, Poema fúnebre a la temprana muerte de la reyna nuestra señora doña María Luisa de Borbón..., 4 hs.; Jacinto Antonio de Fuentes y Padilla, Diálogo que tuvieron la alegría y la tristeza, el día veinte y tres de marzo, en cuyo término se celebraron las honras de la reyna nuestra señora, doña María Luisa de Borbón..., 8 hs; todos ellos, salvo el primero, recogidos en M. Serrano y Sanz, Apuntes..., ob. cit., I, pp. 328-329.

14. Madrid, 1645, f. 95 v.

15. Prodigio lastimoso y fúnebre a la más celebrada princesa D. Isabel de Borbón..., Zaragoza: en la imprenta del Hospital General de Nuestra Señora de Gracia, 1644, f. 22v.; y Joseph Micheli y Márquez, El cristal más puro representando imágenes de divina y humana política..., Zaragoça: Imprenta del Hospital General de Nuestra Señora de Gracia,1644, fol. 22 v. Los datos de esta autora están tomados de BIESES, Bibliografía de Escritoras Espańolas (en la web), donde han sido recogidos por M. ${ }^{a}$ Carmen Marín Pina.

16. S.l.: s.n., 1649, f.62: «En esta elevación farol luciente» $\mathrm{y}$ «Si baja Amor a Dios a ser humano".

17. «No de soberbia no fue de grandeza» (h. 8r.) y "Este marcial cadáver de un ynstante» (h. 8v.); vid. Antonio Rodríguez-Moñino y María Brey Mariño, Catálogo de los manuscritos 
apariciones reiteradas, que son solo parte de una obra más extensa en ambos casos, no las hicieron acreedoras de menciones o reconocimiento adicional, pues ni siquiera Nicolás Antonio llega a citarlas. Y no son una excepción si atendemos a dos homenajes celebrados en fechas muy próximas, donde no hay pretensiones normativas, pero sí una selección implícita que incluye mujeres: Fama pósthuma a la vida y muerte del doctor frey Lope Félix de Vega Carpio, de 1636, y Lágrimas panegíricas a la tenprana muerte del gran poeta $i$ teólogo insigne doctor Juan Pérez de Montalbán, de $1639^{18}$. La visibilidad, la proyección y la atención de los eruditos a este tipo de obras fue nula, puesto que ninguna de las que nos ha dejado un solo poema aquí pasó a las listas de autoras hasta finales del siglo XIX y Bernarda Ferreira de la Cerda y María de Zayas, que aparecen en dos ocasiones, o Violante del Cielo, que solo figura en la Fama pósthuma, se dieron a conocer por otros medios.

En realidad, por su repercusión posterior la fuente de información más relevante sobre las escritoras de este período son las listas que, construidas con diversos propósitos, seleccionan para su elenco demostrativo un cierto número de mujeres sabias. El formato más conocido, el que viene inmediatamente a la memoria, es el de las galerías de mujeres ilustres, si bien la tipología es más amplia y debe ser revisada previamente, ya que la finalidad nunca será ajena al sesgo que adquiera la selección de nombres y por ende su interpretación posible. En primer lugar cabe referirse a esas galerías de mujeres célebres, que son una forma de protohistoria femenina con los antecedentes más remotos en la época clásica (Mulierum virtutes de Plutarco), pero que renace para la edad moderna a finales del siglo XV con De claris mulieribus de Boccaccio y se desarrolla en los siglos siguientes en

poéticos castellanos existentes en la biblioteca de The Hispanic Society of America (siglos XV, XVI $y$ XVII), New York: The Hispanic Society of America, 1965, p. 489.

18. El el primero intervienen: Bernarda Ferreira de la Cerda, Violante del Cielo (monja en el convento de la Rosa en Lisboa), Jusepa Luisa de Chaves, Jacinta Baca, Bitris de Gevora, María de Zayas Sotomayor, Madame Argenis, Madona Fenice, senhora Elisa, señora Peregrina, Antonia Garay, Madama Lisida, Costança Margarita Fontana (monja en el convento de San Leandro de Sevilla); y en el segundo (ed. moderna de Enrico di Pastena, Pisa: edizioni ETS, 2001): María de Zayas, María de Aguirre y Pacheco, María de Salazar Mardones y Aguirre, Inés de Sotomayor (religiosa en el monasterio de Santa Clara de Valladolid), Brígida de Orduña (monja en Santa Paula de Sevilla), Ángela de Mendoça (natural de Granada), Aurelia Antonia de Medrano, Dorotea Felis de Ayala (religiosa en el Real convento de San Antonio de Segovia), Antonia Jacinta de Barreda (natural de Villalpando), Bernarda María (monja en el Real convento de Santa Clara de la ciudad de Salamanca), Juana de Aldana, Petronila de Ávila y Luna (monja en Santa María de las Dueñas de Sevilla), Lorenza de Aguirre y Pacheco, Melchora de Garibay (monja en el convento de la Encarnación del Orden de San Bernardo en Madrid), Madalena Pianeta, Bernarda Ferreira de la Cerda, María de Baraona (religiosa en la Concepción Gerónima de Madrid), Ángela de Sotomayor, María de Aguilera. 
toda Europa como una de las piezas de la llamada querelle des femmes. En definición de Mónica Bolufer «solían consistir en una monografía o tratado constituido por breves reseñas biográficas de personajes femeninos históricos, bíblicos o míticos, clasificados en algunas categorías ya establecidas: mujeres sabias, mujeres heroicas en castidad, en hechos de armas, en "prudencia política» o en el mantenimiento del secreto» ${ }^{19}$. Aunque el conocimiento de los autores españoles no se limitó a las listas publicadas en España, es en las de nuestro país donde podemos encontrar a las españolas que nos interesan, porque rara vez los nombres traspasan las fronteras lingüísticas; también podemos dejar a un lado la extensa bibliografía que produjo el siglo $\mathrm{XV}$ y que en su mayor parte se refiere a mujeres de la antigüedad, santas y reinas ${ }^{20}$.

Los textos a los que nos referiremos son el Diálogo en laude de las mujeres de Juan de Espinosa, la Varia historia de sanctas e illustres mugeres de Pérez de Moya, el Tratado en loor de las mujeres de Cristóbal de Acosta, Le glorie immortali de' trionfi et heroiche imprese d'ottocento quarantacinque donne illustri de Pedro Pablo Ribera, y la "Defensa de la mujer», discurso XVI del Teatro crítico de Benito Feijoo. Aun cuando la tipología a la que adscribimos estas obras es la misma, su género es bien diverso. Pensemos en que Juan de Espinosa se acoge al molde del diálogo renacentista erudito y en consonancia con esta elección también lo son sus fuentes. Por eso, cuando debe recoger ejemplos de mujeres excelentes (o réprobas) solo nombres de la antigüedad greco-latina acuden a su pluma: Aspasia, Nicostrata, Safo, Proba Valeria, etc., como si solo en aquellos tiempos remotos hubiera existido un modelo válido para las mujeres de su época ${ }^{21}$. Pérez de Moya se decanta por el género de la

19. Mónica Bolufer, "Galerías de mujeres ilustres o el sinuoso camino de la excepción a la norma cotidiana", Hispania, LX, 1 (2000), pp. 181-224, p. 184; otras reflexiones interesantes sobre el género, en Carmen Peraita, «Elocuencia y fama: el catálogo de mujeres sabias en la Respuesta de sor Juana Inés», Bulletin of Hispanic Studies, LXXVII (2000), pp. 73-92; Jean Céard, "Listes de femmes savantes au XVI ${ }^{\mathrm{e}}$ siècle», en Colette Nativel, ed., Femmes savantes, savoirs des femmes. Du crépuscule de la Renaissance à l'aube des Lumières. Actes du colloque de Chantilly (22-24 septembre 1995), Genève: Droz, 1999, pp. 85-94; y sobre todo Beatrice Collina, "L'essemplarità delle donne illustri fra Umanesimo e Controriforma», en Donna s disciplina, creanza cristiana dal XV al XVII secolo. Studi e testi a stampa, ed. de G. Zarri, Roma: 1996, pp. 103-119.

20. Por ejemplo, Diego de Valera, Tratado en defensa de virtuosas mujeres (dirigido a la reina doña María), Álvaro de Luna, Libro de las virtuosas e claras mugeres; o Fray Marín de Córdoba, Jardin de nobles doncellas. Vid. Robert Archer, Misoginia y defensa de las mujeres: antología de textos medievales, Madrid: Cátedra, 2001. Uno de los repertorios internacionales más famosos fue la Officina de Ravisio Textor, en cuyo capítulo de «Mulieres doctae», no hay mujeres sabias de origen espańol.

21. Vid. ed. de José López Romero, Granada: Ediciones A. Ubago, 1991, pp. 164-166 y 
biografía y desgrana una tras otra, agrupadas según la virtud más destacada de cada mujer: vírgenes mártires, mujeres de castidad excelente, amantes de su marido, penitentes; después por sus hechos: gobierno y valentía y mujeres doctas. En su afán por promover un ejemplo de virtud para lectura femenina, no se limita a las mujeres de la antigüedad, sino que se acerca sin prejuicios a su actualidad y acude a fuentes como la tradición hispana escrita (pliegos sueltos, crónicas, relatos) y -más reseńable- a la tradición oral de su tiempo. Si prescindimos de santas y reinas, en el apartado de las mujeres doctas no son mayoría las antiguas, sino las modernas, que se agrupan por países o fuentes del autor. Sus nombres, con ser de interés en esta erudición de briznas que debemos practicar, son menos significativos que el hecho de que se recalca la sabiduría unida a la castidad, la obediencia, la santidad, etc., de modo que más parecen destacarse estas virtudes que la inusitada erudición. Para las espańolas cabe subrayar que su fuente de información parece casi siempre oral o al menos solo para las hermanas Luisa y Ángela Sigea (p. 986) remite a Juan Vaseo. Quizá para Francisca de Lebrixa, para Beatriz Galindo (la famosa Latina), o Isabel Joya o de Josa ${ }^{22}$ cabría pensar en información de procedencia escrita, ya que fueron anteriores a su tiempo, pero de muchas como Lorencia Zorita, esposa de Tomás Gracián Dantisco; Catalina de Estrella, nieta de Juan Calvete de Estrella; Isabel de Vega y Catalina de la Paz, poetas de Alcalá (p. 989); o Luciana del Castillo, ubetense (p. 993), por ejemplo, se habla en presente y casi con cercanía, refiriendo datos de sus biografías que no recoge ningún otro testimonio y que de no ser por él se habrían olvidado. Sin duda es el tratadista de miras más amplias y desprejuiciadas, porque no establece a prioris que le impidan mencionar a unas u otras, antes al contrario parece aplicar criterios de inclusión y citar todas las que ha oído nombrar en sus ámbitos de relación: la corte, Alcalá y Úbeda. No será este el proceder habitual ni mucho menos.

Italia y España no compartieron en modo alguno su disposición hacia las escritoras, que allí alcanzaron en el siglo XVI una notable importancia de la cual a nuestra Península no llegaron más que débiles ecos. Sin embargo hubo obras que gozaron de difusión en un lugar y otro. Hay que referirse al Tratado en loor de las mujeres del botánico y moralista portugués Cristóbal de Acosta, aparecido en Venecia en 1592. Aunque no falten algunas referencias a mujeres malas, en conjunto se resalta lo positivo para promover un ejemplo

el estudio «Las fuentes literarias en el siglo XVI: el Diálogo en laude de las mugeres de Juan Espinosa», Philologia Hispalensis, 7 (1992), pp. 55-60.

22. Juan Pérez de Moya, Varia historia de santas e ilustres mujeres en todo género de virtudes (1a ed. 1583), ed. de C. Baranda, Madrid: Fundación José Antonio de Castro, 1998, p. 996; ésta había sido citada anteriormente por García Matamoros, vid. infra. 
cristiano entre las damas seglares, lo que lleva a la inclusión de diversos ejemplos de virtud. En su planteamiento la sabiduría va unida al valor, concepto tan amplio que le permite citar en el mismo capítulo a las reinas o infantas (dońa María, hermana del rey de Portugal; las cuatro hijas de los reyes católicos; Ana, reina de Francia; la marquesa de Mantua, etc.), con Teresa de Jesús, que se elogia como especial ejemplo de virtudes femeninas; y con Oliva Sabuco, cuya obra conoce antes de ser publicada, quizá por su notoriedad en círculos médicos:

Callara yo su nombre hasta el tiempo que lo espero eternizar, quando os embiare (que será presto) el libro que esta sabia muger compone de la nueva filosofia y naturaleza del hombre y de la verdadera medicina. En el qual veréis (vos y quien con consideraçión y sin pasión lo leyere) con mucha agudeza, prudençia y no menos demonstraciones renovada toda la filosofía y medicina, de todos los antigos $[s i c]$ y modernos ${ }^{23}$.

También en Venecia se imprimió el repertorio de mujeres de Pedro Pablo Ribera, una obra que tendrá mucha repercusión en futuros autores. Su listado de espańolas es bastante extenso pero no actualizado, como corresponde al uso esperable de fuentes librescas, Pérez de Moya en particular: Teresa de Jesús, María de Urrea, condesa de Alvadaliste, Catalina de Ribera, Beatriz Galindo, Luisa Sigea, Ángela Sigea, Catalina Estrella, Luciana del Castillo, Isabel Rosales, Catalina Trillo, María Saviote Maldonado, Oliva Sabuco, Lorenza Zorita, Juana Bautista y Magdalena Bobadilla ${ }^{24}$.

Saltando por encima de Martín Carrillo y sus Elogios de mugeres insignes del viejo Testamento (Huesca, 1627), porque solo atiende a retratos bíblicos, nos llegaremos hasta Benito Feijoo, en el discurso XVI del Teatro crítico, "Defensa de la mujer» ${ }^{25}$. En sus últimos apartados entra en la cuestión del entendimiento de las mujeres y recurre a ilustres ejemplos para probarlo:

23. Cristóbal Acosta, Tratado en loor de las mujeres y de la castidad, onestidad, constancia, silencio, y iusticia: con otras muchas particularidades, y carias historias. Dirigido a la serenissima sennora Infanta donna Catalina d'Austria..., Venecia: Giacomo Cornetti, 1592, ff. 106v-107r. Aunque la obra no se publicó hasta 1592, la epístola inicial va fechada en Valladolid a 12 de agosto de 1585, lo que explica la referencia como futuro al libro de Sabuco, que apareció en Madrid: Pedro Madrigal, 1588.

24. Ribera, Pedro Pablo, Le glorie immortali de' trionfi et heroiche imprese d'ottocento quarantacinque donne illustri antiche e moderne dotate di conditioni e scienze segnalate: Cioè in sacra Scrittura, Teologia, Profetia, Filosofia, Retorica, Gramatica, Medicina, Astrologia, Leggi Civili, pittura, musica, armi \& in altre virtù principali, Venetia: Evangelista Deuchino, 1609, pp. 291-295, 304-309 y 329-333. De todas las citadas, Isabel Rosales es la única que no estaba en Pérez de Moya y que habrá que derivar de la obra de Cristóbal de Acosta.

25. Ed. exenta de Victoria Sau, Barcelona: Icaria, 1997. 
Ana Cervatón, Isabel de Joya, Luisa Sigea, Oliva Sabuco (conoce su obra directamente), Bernarda Ferreira de Lacerda, Juliana Morella, Sor Juana Inés de la Cruz y la duquesa de Aveiro. Hay una pequeña semblanza de cada una de ellas, en la que se pone de relieve ante todo la erudición y el ámbito público en el que fue reconocida, lo que para Feijoo parece constituir garantía de su valor, más allá de la obra en sí misma: Ana de Cervatón fue celebradísima en la corte de Germana de Foix; Isabel de Joya predicó en Barcelona y en Roma, para asombro de todos; Luisa Sigea dominó lenguas clásicas y fue llamada por la Infanta María a su corte; Bernarda Ferreira fue elogiada por Lope de Vega; Juliana Morella dedicó una obra a la reina Margarita de Austria y disputaba públicamente en Lyon. Oliva Sabuco es, sin duda, quien más admiración despierta por dar lugar a un nuevo sistema "fisiológico y médico", cuyas hipótesis han sido luego sostenidas por Descartes. Esto le sirve a Feijoo para insistir en uno de sus motivos recurrentes, el desdén de Espańa por sus propios sabios en favor de los extranjeros. A nuestros ojos hay que hacer entre ellas grandes diferencias, porque Ana Cervatón, Isabel de Joya y Juliana Morella apenas son algo más que leyendas eruditas sin ninguna base documentable o escrita sólida, mientras que las tres restantes tienen una obra singular y reconocible, susceptible de una valoración propia en la tradición letrada. Feijoo las hace iguales en su nómina, porque ninguna es autora de una obra con título, sino de «escritos», que junto con su sabiduría son causa de una difusa fama que disfrutaron en su ya lejano momento. Las ha subido a un pedestal de vaguedades que las ubica fuera de una realidad histórica concreta y revisable.

Entre sus casi coetáneas, Feijoo destaca a Sor Juana Inés de la Cruz y la duquesa de Aveiro. Su trato es muy desigual: de la Duquesa es «ocioso el panegírico... porque están bien recientes sus noticias en la corte...»; de la monja mexicana reprueba la poesía: «solo diré que lo menos que tuvo fue el talento para la poesía, aunque es el que más se celebra. Son muchos los poetas españoles que la hacen grandes ventajas en el numen; pero ninguno la igualó en la universalidad de noticias de todas facultades» ${ }^{26}$. Si en Julia Morella le parecía bien que disputara públicamente en el colegio de jesuitas de Lyon o que Isabel de Joya explicara muchos puntos difíciles de Escoto a los mismísimos cardenales, no le parece tan loable que Sor Juana criticara un sermón del P. Vieira, ya que su agudeza «es mucho menor que la de aquel incomparable jesuita a quien impugna. ¿Y qué mucho que fuese una mujer inferior a aquel hombre, a quien en pensar con elevación, discurrir con agudeza y explicarse con claridad no igualó hasta ahora predicador alguno?».

26. Ibidem, p. 62, de donde se toma asimismo la cita siguiente. 
Enfrentado a la fama innegable de sor Juana Inés de la Cruz, presente en la mente de sus coetáneos, se aviene a mencionarla, pero no para ensalzarla como ejemplo máximo reconocible de sus tesis sobre el saber de las mujeres, sino al contrario para rebajar sus méritos: su poesía está por debajo de la de muchos poetas y su capacidad de elevación, discurso o agudeza no llega a igualar las del P. Vieira.

Feijoo ha hecho una selección férrea de sus fuentes, quizá para establecer un equilibrio expositivo entre las ocho españolas, las siete francesas e italianas respectivamente y una alemana. Pero la ha realizado bajo la preferencia de una cómoda distancia temporal aureolada con matices difusos de erudición, alejada de la concreción de los datos, que le hacen sentirse incómodo cuando debe someterlos a contraste real en su serie histórica. Por eso no recurre a Nicolás Antonio, que hubiera podido representar una fuente inestimable para su propósito ${ }^{27}$. Saber femenino sí, pero mejor silencioso.

Merece la pena introducir en este punto, por el contraste interpretativo que permite, la elogiosa mención que Francisco Bances Candamo dedica a sor Juana Inés:

Sobre todo nos han impresso, pocos días á, dos libros de Soror Juana de la Cruz, religiosa en México, de que resulta más clara que de todos los otros esta prueba: porque una muger, encerrada desde niña en un monasterio en lo más remoto del occidente, toca cosas que nunca pudo ver, demuestra facultades que no pudo estudiar, y se arroja con el spíritu a cosas que parece temeridad emprender ${ }^{28}$.

Para Bances el espíritu poético preexiste al poeta y no hay mejor prueba de ello que la sorprendente monja mexicana, ya que no es posible concebir que su obra sea el resultado de un proceso de estudio, es decir, de ese conocimiento racional y esfuerzo intelectual que siempre se daría por supuesto que hay detrás de las obras de cualquier hombre. Una obra relevante escrita por una mujer es un acontecimiento extraño que inquieta a ambos hombres y que

27. La primera edición de la Bibliotheca Hispana Nova apareció en Roma: Nicolai Angeli Tinassii, 1672; sobre el contraste entre una y otra obra vid. infra. De momento cabe señalar que Feijoo podía haber distinguido entre las autoras de haber consultado esta obra, ya que en ella Ana Cervatón, Isabel Joya y Juliana Morella no tienen entrada más que en la lista del gineceo, mientras que las tres restantes reciben una atención particular en la parte general de la Bibliotheca nova entre los autores.

28. Theatro de los theatros de los passados y presentes siglos, ed. D. W. Moir, Londres: Tamesis, 1970, p. 94; se trataría de una de las primeras menciones en la Península de la obra de sor Juana, publicada en 1689, pues esta tercera versión se data entre 1692-1694. 
se explican de formas opuestas: Bances por la inspiración ajena al estudio; Feijoo minusvalorando la obra para ponderar su capacidad de asimilación intelectual.

Los repertorios dedicados solo a las mujeres (defensa o vituperio) se sitúan en el ghetto de lo femenino, que identifica a las figuras incluidas antes como mujeres (término marcado frente al masculino neutro) que como modelos de actuación. Quizá por esta razón suelen ser más visibles y por ende citadas las escritoras mencionadas en obras donde van a la par de los escritores, aunque eso no significa que se vean mezcladas con ellos. El repaso debe comenzar por Lucio Marineo Sículo, que se refiere a mujeres eruditas en dos obras: sus Epistolarum familiarum (1514) y De rebus hispaniae memorabilibus (1530). En la primera se trata de una mención indirecta, al destinar cartas en latín a dos damas, esposas de hombres notables que le habían protegido: Ana Cabrera, esposa del Almirante Fadrique Enríquez, con quien había venido a España; y María Velasco, esposa de Juan Velázquez, de cuyos hijos fue maestro; y a tres «doncellas sabias»: Juana Contreras, Ana Cervató y Lucía de Medrano. Al tratarse de epístolas latinas parece indicar que todas esas mujeres dominaban la lengua clásica, si bien con la diferencia de que en los tres últimos casos la epístola está destinada a elogiar la erudición de la destinataria, con la que (se desprende) mantiene una correspondencia de corte erudito. Solo en el caso de Ana Cervató tenemos constancia directa de esta erudición, por la inclusión de una carta suya que M. Sículo utiliza para darle una lección de expresión latina ${ }^{29}$. Años más tarde, en De rebus Hispaniae memorabilibus, incorpora una pequeña galería de mujeres ilustres que amén de las anteriores (con excepción de Ana Cervató) incluye a Beatriz Galindo, a las hijas del Conde de Tendilla (María Pacheco, esposa del comunero Padilla; y María de Mendoza, Condesa de Monteagudo), a Ángela Carlet, a una prima suya, que según cree se llama Leonor, y a Isabel de Vergara ${ }^{30}$. En ambos casos, cabe destacar que Lucio Marineo elogia la erudición clásica de estas mujeres en sí misma, sin añadir que destacaran por su santidad, su virtud o moralidad, situadas en grupos aparte. Son pocas,

29. Véase Teresa Jiménez Calvente, Un siciliano en la España de los Reyes Católicos. Los «Epistolarum familiarum libri XVII» de Lucio Marineo Sículo, Alcalá de Henares: Universidad, 2001, p. 754. En el documentado estudio preliminar, p. 142, nos recuerda cómo en la carta a doña María de Velasco alude a su intención de hacer una obra De illustribus mulieribus, que nunca llegó a concluir y cuyo resto sería el apartado final en De rebus Hispaniae memorabilibus.

30. Alcalá: Miguel Eguía, 1530, ff. 174v. Un comentario sobre el peso de M. Sículo en la tradición historiográfica femenina en N. Baranda, «Mujeres y cultura...» art. cit. supra., n. 2. 
frente al conjunto de mujeres mencionadas por su lealtad, valor, castidad, etc., pero indica que el conocimiento, la erudición, es en sí mismo virtus, sin necesidad de ir acompañado por otros valores morales o quizá sea que para Sículo los llevaba implícitos. Eso no quiere decir que sean escritoras, basta con que dominen las lenguas clásicas para un saber silencioso o privado. Solo de Angela Carlet y Juana Contreras se dice que hayan producido algo propio, después de haber dejado a Ana Cervató en el olvido ${ }^{31}$.

La controversia antiguos y modernos, que no se apreciaba en Lucio Marineo Sículo, está presente en Alfonso García Matamoros Pro adserenda hispanorum eruditione (1553) ${ }^{32}$, que recoge seis mujeres sabias «prodeat etiam in aciem lectissimus feminarum chorus, qui de ingenio \& doctrinae laude cum Graecis \& Latinis generose admodum certet»: la duquesa de Calabria, Mencía de Mendoza, se podría equiparar a la Aspasia de Jenofonte por su erudición griega y latina, y su fervor por el estudio; «Isabella Ioensis, nobilis femina Barcinonensis, optimarum litterarum studio \& vigilantis ingenii» es similar a Paula Romana por su conducta; "Angelam Zapatam, quae quum angelica mente donata esset», alabada por Luis Vives; «Sigaeam Toletanam, quam propter litteras Latinas, Graecas \& Hebraicas serenissima Lusitanae regina intra aulam suam incredibili admiratione excepit» compartía con otras doncellas su honesta conversación; "Annam de Osorio Burgensem, \& maiorum imaginibus nobilem \& divinae Theologiae studio celebrem». En ellas el saber se acompaña en todo momento de virtud o conocimiento teológico. Solo Catalina Paz, a quien el autor conoció personalmente en Alcalá, despierta su entusiasmo como poeta exquisita muerta en su juventud, sin alusión a una honestidad femenina:

E quarum specioso conspicuoque grege unius mulieris Latini versus sacris saepe \& publici certaminibus primam Hispali \& Compluti lauream iudicium sententia meruerunt? (...) quos poesis fontes subito fortuna prostavit? quae non litterae politiores cum illa mortuae $\&$ sepultae fuerunt ${ }^{33}$ ?

31. Para los planteamientos del humanismo, la educación femenina era un adorno que proporcionaba mayor valor a la mujer a la hora de tomar estado por la utilidad que suponía para la educación de los hijos. Destinar estos saberes a la función pública o a la simple escritura no estaba previsto ni alentado, vid. Lisa Jardine, «Women Humanists: Education for What?», en Lorna Hutson, ed., Feminism and Renaissance Studies, Oxford: University Press, 1999, pp. 48-81.

32. Ed. bilingüe de José López de Toro, Madrid: Consejo Superior de Investigaciones Científicas, 1943, las eruditas en pp. 228-229.

33. Ibidem, p. 228. Es muy interesante la referencia a su participación en certámenes de Sevilla y Alcalá, porque sería el primer caso conocido de una mujer que toma parte en una justa, aunque no hay más rastros. Conservamos tan solo dos poemas latinos en los 
No podemos saber si también conocía la existencia de Isabel de Vega, a la que Pérez de Moya citaba como alcalaína, pero en todo caso se percibe en García Matamoros que el saber pasa por las lenguas clásicas, como corresponde a un erudito de su época y a quien ha acudido a Lucio Marineo Sículo como fuente privilegiada.

El repertorio de Andreas Schott es parecido, porque entre los cientos de nombres que componen su Hispaniae Bibliotheca solo tiene lugar para doce mujeres notables de su tiempo comentadas bajo el epígrafe IX de foeminarum eruditarum ${ }^{34}$ : Mencía de Mendoza, Isabel Joya, Luisa y Ángela Sigea, Ana Osorio, Catalina Paz, Catalina Trillo, Beatriz Galindo, Ángela Zapata, Oliva Sabuco, Teresa de Jesús y Juliana Morell. Lo interesante no es solo la selección de nombres, que remite en cita a Vives o Pérez de Moya, sino la aparente necesidad de convertirlas en objeto de comentario, restando a su autoría, y de reducirlas a su condición femenina. Así Teresa de Jesús queda excluida de la lista de carmelitas que había unas páginas antes en la obra para figurar en esta de mujeres, donde no se hace tanto hincapié en su autoría, que es algo desdibujado sobre su vida religiosa y meditaciones, como en el hecho de que el jesuita Francisco Ribera hubiera escrito su biografía, obra concreta traducida incluso al francés: «Scripsit eum de sua vocatione ac vita religiosa, tum meditationes pias. Edidit quoque de eius pia vita hispano sermone \& gallice redditur P. Franciscus Ribera societ. Iesu Theologus» ${ }^{35}$. En el caso de Luisa Sigea lo que autoriza su saber son los epitafios o versos laudatorios que le dedicaron Juan Merulo, Andrés Resende, Francisco López, Álvaro Gómez y Juan Vaseo, reproducidos en parte; nada dice sobre el poema Syntra, donde esos textos fueron publicados por vez primera. Solo a Oliva Sabuco la trata como a los autores, es decir, sí da el título de la obra con dato preciso de la fecha de edición en 1588 y reseńa que está dedicada a Felipe II. La selección de datos y el filtro de reelaboración que se les aplica siguen unos mismos criterios de exclusión.

El cronista real Tomás de Tamayo de Vargas al hacer un intento de bibliografía española no deja de lado a las escritoras. Su Iunta de libros, la

preliminares del Buen plazer trobado de Juan Hurtado de Mendoza (Alcalá, 1550) y otros dos manuscritos, vid. J. F. Alcina, Repertorio de la poesía latina del Renacimiento en España, Salamanca: Universidad, 1995, p. 162.

34. Hispaniae Bibliotheca seu de academiis ac bibliothecis. Item elogia et nomenclator clarorum Hispaniae scriptorum, qui latine disciplinas omnes illustrarunt philologiae, philosophiae, medicinae, iurisprudentiae, ac theologiae, tomis III, Francofurti: Claudium Marnium \& haeredes Ioan. Aubri, 1608, pp. 340-344

35. Ibidem, p. 343. 
maior que España ha visto en su lengua hasta el año de MDCXXIV ${ }^{36}$ incluye en el lugar alfabético que le corresponde a cada uno la cita escueta de los nombres y los títulos de las obras impresas con autoría femenina, dando los datos de impresión necesarios. A partir de su Junta se recuperan ediciones desde mediados del XVI a 1624: Beatriz Bernal, Feliciana Enríquez de Guzmán, Francisca de los Ríos, Magdalena de S. Jerónimo, María Téllez, Oliva Sabuco, Teresa de Jesús y Valentina Pinelo, a cuyos nombres es capaz de adjuntar algún dato biográfico que hubo de obtener de los prólogos o preliminares, lo que nos asegura que consultó al menos mínimamente cada una de las obras. No cabe duda de que se echan de menos otros, quizá por desconocimiento: Isabel de Liańo o Bernarda Ferreira de Lacerda, pero en todo caso es un trabajo casi exhaustivo y supone la primera vez en que se citan de forma fehaciente esas obras concretas, más allá del aroma a erudición, que era el único atributo de la mujer sabia excepcional, del olvido o del paternalismo discriminatorio en la glosa al que sometían a las escritoras otras fuentes.

También la Bibliotheca hispana nova de Nicolás Antonio tiene ese mismo carácter de repertorio de escritores donde las mujeres se insertan a la par, al menos fuera del apéndice Gynaeceum hispanae minervae. El alcance y sentido de esta magna compilación de carácter erudito e inspirada por una voluntad historiográfica difiere, como Tamayo, de las anteriores, y si aquí se sitúa junto a ellas es por el hecho de que equipara en el trato a las escritoras con los escritores; no obstante la información que aporta va mucho más allá. Su importancia estriba en que por primera vez de forma impresa y notoria se escogen casi exclusivamente creadoras, productoras de textos, y se dan datos precisos sobre sus obras, de modo que las vagas nociones anteriores quedan totalmente superadas. Ninguna de las autoras lo es salvo que tenga a su nombre obras que lo justifiquen, ya sean impresas (la mayoría) o manuscritas, y solo en el caso de Joanna Baptista, remite a una fuente secundaria declarada ${ }^{37}$, ya que no tiene otras referencias. De hecho, hasta no llegar a Serrano y Sanz es imposible encontrar mejor y más riguroso repertorio de la escritura femenina hispana del Siglo de Oro, porque en todos los casos, con pocos errores y confusiones, se trata de noticias fiables, que recogen ediciones hoy conocidas, lo que nos garantiza que citaba a partir de un manejo directo.

36. BNE, Ms. 9752-53.

37. Empleo el facsímil de la ed. de Madrid: Viuda de Joaquín Ibarra, 1788, publicado en Madrid: Visor, 1996, t. I, p. 626; la fuente citada es Pietro Paulo Ribera, Glorie immortali..., que ya hemos reseñado. 
Ahora bien, el rasgo de modernidad que ofrece la Bibliotheca no se continúa en el Gynaeceum, donde volvemos a la segregación de género y al acopio indiscriminado de noticias, que aunque con mucha mayor riqueza y documentación que antes, vuelven a equiparar doctas con escritoras, cultas con virtuosas o santas, siguiendo en esto, ahora sí, fuentes secundarias, en gran medida material mostrenco. Y por desgracia, entre las escritoras incluidas en el lugar alfabético correspondiente y las mujeres de varia erudición o saber que se acopian en el Gynaeceum, fue éste el lugar más visible, el que volvió a actuar como imán para citas y referencias posteriores ${ }^{38}$. Ciertamente existe vacilación entre los bibliógrafos y eruditos, pues unos optan por intercalar a las mujeres en su orden alfabético correspondiente, equiparándolas simbólicamente con los autores al no establecer discriminación de género; mientras que otros prefieren mantener el uso tradicional que construye para ellas un capítulo propio y, por tanto, las segrega como diferentes de los hombres ${ }^{39}$.

El siglo XVIII, caracterizado como de la razón y las luces e inicio de la historiografía literaria propiamente dicha, no muestra novedades en el trato que da a las escritoras. Ya se señalaba anteriormente cómo Feijoo, en su Teatro crítico, renuncia a seguir los pasos de una fuente rigurosa como N. Antonio para acogerse a las vaguedades autoriales, lo mismo que seguirán haciendo las galerías de mujeres célebres posteriores, que no se extinguen, sino que aprenden a adaptarse y ofrecer en cada caso lecturas distintas, concordantes con las intenciones de los autores y las transformaciones sociales en el papel de las mujeres. Bien es verdad que estas nuevas galerías con todos sus errores acusan el espíritu positivista, de modo que los perfiles de las autoras ganan en concreción y se citan incluso algunas de sus obras, así D. de Froes Perym, a pesar de ser portugués, incluye a un gran número

38. Sobre las escritoras en la obra de N. Antonio vid. Lola Luna, «Las escritoras en la Bibliotheca de Nicolás Antonio», en Leyendo como una mujer la imagen de la mujer, Barcelona: Anthropos, 1996, pp. 28-40; y François Géal, «Nicolás Antonio juge de la femme de lettres à travers la Bibliotheca Hispana Nova», en Relations entre hommes et femmes, ob. cit., pp. 39-52.

39. Intercala a las autoras Vicente Ximeno, Escritores del reyno de Valencia, chronológicamente ordenados desde el año MCCXXXVIII de la christiana conquista de la misma ciudad, hasta el de MDCCXLVII, Valencia: Joseph Estevan Dolz, 1747-49, 2 ts. (facsímil de Valencia: Librerías París-Valencia, 1980); y les da un capítulo aparte Joseph Rodríguez, Biblioteca valentina, Valencia: Joseph Tomás Lucas, 1747 (facsímil de Valencia: Librerías París-Valencia, 1980). No es esta la única diferencia entre ambas obras, ya que Ximénez es mucho más fiable en sus datos y al igual que N. Antonio, salvo en un caso, todas las mujeres son autoras, con obras identificadas a su nombre e incluso con localización de las mismas cuando se trata de manuscritos. 
de las escritoras que estaban en N. Antonio, pero también otras nuevas, posteriores o coetáneas a Antonio: Ángela de Azevedo, María Guadalupe Lancastro e Cárdenas, Leonor de Meneses, sor Juana Inés de la Cruz; e igual procedimiento observamos en J. B. Cubié, que incorpora como nuevas a María Nieto de Aragón o Beatriz de Silva e Sousa, siempre sin distinguir sabias y valerosas de autoras, como era habitual ${ }^{40}$.

No obstante, en nuestra revisión histórica el centro de interés debe pasar de estas galerías de mujeres célebres a esa nueva forma de parnaso que constituyen las historias de la literatura, que nacen en este período. La crítica especializada en el tema suele darle el lugar de apertura a las Memorias para la historia de la poesía del P. Sarmiento (1785), pero en nuestro caso el honor de abrir brecha hay que concedérselo al Ensayo histórico-apologético de la literatura española del Abate Lampillas, traducida del italiano precisamente por una mujer, Josefa de Amar y Borbón ${ }^{41}$. Aquí se incorporan muchas de las citadas en las listas del Siglo de Oro, junto a otras nuevas (ninguna, por cierto, del siglo XVIII), pero la importancia de este Ensayo no radica tanto en la mención novedosa, como en el hecho de que estas autoras figuran dentro de una historia de la literatura, es decir, en un contexto que no está marcado como exclusivamente femenino, en el cual, si bien no reciben demasiada atención, se agrupan por criterios poco acertados o se clasifican bajo el concepto de "mujeres en...", no dejan de ser un grupo que empieza a tomar perfiles diacrónicos.

Retroceder nuevamente a mediados del siglo XVI para revisar listas elaboradas por poetas en vez de eruditos nos deparará la sorpresa de que ambos grupos, en lo que a mujeres escritoras se refiere, parecen seguir cauces paralelos, sin apenas interferirse o cruzar sus datos. Los nombres que

40. Damiaó de Froes Perym, Theatro heroino; abecedario historico e catalogo das mulheres illustres em armas, letras, acçoens heroicas e artes liberaes, Lisboa: Officina de Musica de T. Antunes Lima, 1736-1740, 2 ts.; y Juan Bautista Cubié, Las mugeres vindicadas de las calumnias de los hombres. Con un catálogo de las españolas que más se han distinguido en ciencias y armas, Madrid: Impta. de Antonio Pérez de Soto, 1768 (hay facsímil en Valladolid: Editorial Maxtor, 2001).

41. Lampillas, Xavier, Ensayo histórico-apologético de la literatura española contra las opiniones preocupadas de algunos escritores modernos italianos. Disertaciones del señor abade don Xavier Lampillas. Parte segunda de la literatura moderna. Traducido del italiano al español por doña Josefa Amar y Borbón, residente en la ciudad de Zaragoza, socia de mérito de la Real Sociedad Económica Aragonesa de Amigos del Pais. Con licencia y privilegio, Zaragoza: Oficina de Blas Miedes, 1783-1786, 5 vols. En su obra aprovecha tanto a Nicolás Antonio como a Vicente Ximénez, lo que no quiere decir que incluya ni mucho menos a todas las autoras que ambos mencionan. 
recogen de forma más machacona esas bibliothecas no tienen relevancia en las nóminas parnasianas del Siglo de Oro. Ya vimos cómo había algunos poemas y menciones en el XVI de Isabel de Vega y Catalina Paz, sin embargo ambas o cualquier otra están ausentes de los cantos fluviales al uso, donde se evocan poetas ilustres y amigos. Vale para comprobarlo el repaso de algunos de ellos: el "Canto del Turia» en Diana enamorada de Gaspar Gil Polo (1564), la epístola inicial de Las abidas de Jerónimo Arbolanche (1566), el "Canto Pinciano» de J. de Lomas Cantoral (1578), el «Viaje de Sannio» de Juan de la Cueva (1582), el «Canto de Calíope», que Cervantes inserta en el último libro de La Galatea (1585) o el Viaje del Parnaso que hizo después. Pero no hay solo un silencio, sino también puede producirse un comentario abiertamente hostil a las mujeres que escriben, que son consideradas deshonestas:

\footnotetext{
Ni soy yo [el autor] como Sapho la ramera/ que al gentil Aphaon amava tanto/ que quiso con sus versos de hechizera/ metelle baxo su lascivo manto,/ ni como Circe, la poetisa fiera,/ en puercos bolveré con dulce canto/ a los hombres, ni querré yo como Herina/ desesperado echarme en la marina ${ }^{42}$.
}

Más intolerante aún se mostrará Diego de Saavedra Fajardo en la República literaria, quizá porque para 1612 la existencia de mujeres escritoras o versificadoras sin más había eclosionado y no podía ser ignorada, lo que suscitó un rechazo directo en muchos autores, traducido en sátiras y en la aparición de términos despectivos como bachillera o latiniparla entre otros:

\footnotetext{
Dejando, pues, en su tema a aquellos filósofos, doblé una esquina, y vi salir de su casa a Safo, las faldas en la mano, huyendo de la ira de su padre. Detúvele, y diome muchas quejas de su hija, que, divertida en hacer versos, había olvidado los oficios y ejercicios caseros de coser y hilar, que es la sciencia más digna y propia de las mujeres, a quien deben aplicar toda su atención y gloria, y no a los estudios, que distraen sus ánimos, y vanamente presuntuosas de lo que saben, procuran las conferencias y disputas con los hombres, olvidadas de su natural recogimiento y decoro, con evidente peligro de su honestidad. Harta lástima tuve al viejo padre, a quien el estudioso divertimento de la hija y sus liviandades, bien conocidas en aquella ciudad, daban mala vejez ${ }^{43}$.
}

42. Jerónimo Arbolanche, Las abidas, ed. de F. González Ollé, Madrid: CSIC, 1972 (Col. Clásicos Hispánicos) t. II, p. 355 del facsímil.

43. República literaria, ed. de J. C. de Torres, Barcelona: Plaza \& Janés, 1985, p. 145 . 
No se trata de una actitud unánime, por supuesto. Vicente Espinel en sus Diversas rimas (1591) pone entre los paratextos un soneto de Catalina Zamudio, «El que con tierna voz del reino oscuro», lo que entonces era algo insólito y, más aún, inserta varias damas en su "Casa de la memoria». Francisca de Guzmán, Isabel Coello, Ana Zuazo y Agustina Torres no figuran como poetas, sino como músicas, pero lo mismo que están presentes Cabezón, Salinas o Guerrero ${ }^{44}$. El elogio procedía del conocimiento personal, quizá del deseo de halagar, porque Espinel acudía a casa de doña Ana Zuazo, donde se celebraban sesiones musicales. Estos motivos $\mathrm{u}$ otros no restan valor a su presencia en un posible parnaso salmantino, donde por vez primera las damas no son solo hermosas y discretas, es decir, adorno de caballeros, sino también agentes en la producción artística.

Podemos considerar a Espinel como cabeza de una tendencia que acababa de iniciarse y que se ampliaría en los decenios sucesivos. Lope, tan atento a novedades, acusó su impacto. En el romance que incluye en El peregrino en su patria (1604) aparecen como valores de su actualidad, que compite ventajosamente con Nicostrata o Safo: Laurencia Zurita, Oliva de Nantes (es decir, Sabuco), Valentina Pinelo, María Enríquez («que oy llora Tormes»), doña Ana de Zuaço y María de los Cobos. Salvo Oliva Sabuco, famosa por La nueva filosofía de la naturaleza del hombre, el resto parecen haber tenido un contacto personal con Lope en los ańos precedentes: era amigo de Tomás Gracián Dantisco, esposo de Laurencia Zurita; a la Vida de Santa Ana (Sevilla, 1604) de Valentina Pinelo le dedicó varios poemas panegíricos en preliminares, escritos en Sevilla por los mismos años en que está terminando este Peregrino; de su etapa de Alba de Tormes (1590-95) procede la mención de María Enríquez, esposa del III Duque de Alba; momento en que quizá conoció también a Ana de Zuazo, a quien Espinel ubicaba en Salamanca. Sobre María de los Cobos no hay ningún dato adicional ${ }^{45}$.

44. Diversas rimas (1591), ed. de A. Navarro González y P. González Velasco, Salamanca: Universidad, 1980, pp. 122-124. Sobre estos primeros poemas femeninos en paratextos vid. N. Baranda, «Escritoras sin fronteras entre Portugal y España en el Siglo de Oro (con unas notas sobre dos poemas femeninos del siglo XVI)", Península. Revista de Estudos Ibéricos, 2 (2005), pp. 219-236.

45. El comentario sobre cada una de ellas es muy general, apenas algo que no sea un elogio hiperbólico y si acaso su procedencia geográfica vid. ed. de J. B. Avalle-Arce, Madrid: Castalia, 1973, pp. 379-380. Estas mujeres han sido estudiadas por Simon A. Vosters, «Lope de Vega y las damas doctas", en Actas del III Congreso internacional de hispanistas, celebrado en México D. F. del 26 al 31 de agosto de 1968, ed. de Carlos H. Magis, México: Asociación Internacional de Hispanistas/ El Colegio de México, 1970, pp. 909-921; e ídem, «Lope de Vega y Juan Ravisio Textor. Nuevos datos", en Actas del IV Congreso internacional de hispanistas, celebrado en Salamanca, agosto de 1971, ed. de Eugenio Bustos Tovar, Salamanca: 
Después del Peregrino es inevitable pasar por los versos del Laurel de Apolo (1630), que entre unos trescientos poetas contados por su editor moderno incluye doce escritoras, algunas por acarreo cercano y otras por conocimiento directo. En el Tajo, Ana de Ayala, con tanta hermosura como entendimiento, de quien «aprenden las aves números dulces»; Clara de Barrionuevo autora de versos «tan felices»; Isabel de Rivadenayra, «sus rimas de conceptos llenas,/ exceden las de Laura Terracina»; Laurencia Zurita, admiración del mundo, que "escribió sacros himnos» en latín; Ana de Castro, que está en la corte: «y pues das a Felipe eternidades,/ reserva para ti siglos de edades» ${ }^{46}$. En Indias, Amarilis de Santa Fe de Bogotá, Jerónima Velasco en Quito (Silva II, vv. 167-183). Bernarda Ferreira, autora de la España libertada, que con su «dulce historia,/ con tanta erudición, con tanto lustre,/ que ella queda inmortal y España ilustre» (Silva III, vv. 194-205); la ignota Feliciana, estudiante en Salamanca disfrazada de varón (Silva III, vv. 440-525); Beatriz Galindo, nombrada como «aquella latina... docta con hermosura,/ y santa en lo difícil de la corte» (Silva V, vv. 50-54); Ana de Zuazo, «donde con tierno abrazo/ se juntaron las Gracias y las Musas... hablaba flores y cantaba cielos» (Silva VIII, vv. 355-369); y María de Zayas, «su ingenio, vivamente claro/ es tan único y raro» que puede dar al Manzanares tanta fama como Claudia a Nápoles, Cornelia a Roma o Targelia a Tebas (Silva VIII, vv. 579596). En los veinticinco ańos que median entre el Peregrino y el Laurel se ha olvidado de Oliva Sabuco, de Valentina Pinelo, María Enríquez y María de los Cobos. Claro que tampoco recuerda a las muchas que participaron en las justas toledanas o madrileńas que él había organizado en Toledo (1605 y 1608) y en Madrid (1615) ni a Catalina Trillo, Isabel de Figueroa o Catalina Zamudio, a quienes había pedido versos para los preliminares de sus obras. Por otro lado, a su muerte, en la compilación titulada Fama pósthuma que hizo Juan Pérez de Montalbán como homenaje al amigo (Madrid, 1636), solo Bernarda Ferreira de Lacerda y María de Zayas coinciden con la lista del Parnaso, y ellas repetirán en las Lágrimas panegíricas a la muerte de Juan Pérez de Montalbán (Madrid, 1639). ¿Porque las demás han muerto para entonces? (¿todas?), ¿vivían lejos y sus versos no llegaron a tiempo? (pero sí los hay de monjas de otras ciudades como Sevilla, Salamanca o Segovia), ¿'no quisieron participar? ¿A ellas no se les pidieron versos?, ¿por qué? (¿desconocidas, ilocalizables, irrelevantes?). Más preguntas que respuestas en torno a la lista más extensa de toda la época, que quizá solo haya que interpretar siguiendo

Asociación Internacional de Hispanistas, 1982, t. II pp. 785-790.

46. Ed. de Christian Giaffreda, Firenze: Alinea Editrice, 2002, Silva I, vv. 519-547, 608-631, 647-668, aunque ahora hay también ed. muy accesible de A. Carreño, Madrid: Cátedra, 2007. 
los vaivenes vitales e impulsos de Lope en aras de lo que pedía el instante, la moda, la conveniencia o la rapidez compositiva, sin más.

La tradición del Laurel de Lope se prolonga en Gutierre Marqués de Careaga, que, como contribución al homenaje a Juan Pérez de Montalbán (1639) ${ }^{47}$, redacta un elogio de la poesía de su tiempo, en el que se mencionan sobre todo hombres, junto a algunas mujeres célebres por su saber: bíblicas, antiguas y modernas, españolas e italianas. Frente a otras citas, las de Marqués de Careaga se detienen en cada una de las autoras, sobre todo para dar algunos datos biográficos o referencias de su mayor mérito. De Santa Teresa, a la que elogia como santa del Carmelo, no alude a sus obras en prosa, para entonces tan conocidas, sino a sus poemas: "compuso muchos versos, sentenciosos y dulces». Además recuerda la dedicatoria que Bernarda Ferreira de Lacerda hizo a Lope en las Soledades de Busaco (Lisboa, 1634), de la que incluso cita unos versos. Después de las romanas y las italianas, entrarán las españolas. A través de Lucio Marineo Sículo, incluye a Beatriz Galindo, erudita por su latín y maestra de la reina Católica; y a Lucía de Medrano, como oradora en la universidad de Salamanca. La mención de las siguientes podría provenir de Pérez de Moya, puesto que hay sintagmas enteros de texto idénticos: recuerda a Catalina de la Estrella por haber sido celebrada como prodigio, debido a su conocimiento de latín, italiano, francés e historia; a Cecilia Morillas, como educadora de siete hijos varones, a quienes enseñó gramática, retórica y griego ${ }^{48}$; a Luisa y Ángela Sigea por su erudición latina y en otras lenguas. Un último grupo debe considerarse conocido a través de su experiencia directa: Oliva Sabuco, de quien menciona el libro impreso y dice que fue maestra de retórica y gramática en Alcaraz; y dos coetáneas: María Díez, que vivía «en la de Salamanca, en mi tiempo y el de mi asistencia en ella, desde el ańo 1600, en los doze de mi edad», monja del Convento de Santa Ana, famosa por sus versos; y Juliana Morelle, gran conocedora del latín, griego y hebreo, quien como una nueva doncella Teodor a los doce años se exhibió ante la reina Margarita de Austria. Solo con seguir a Pérez de Moya podía haber citado muchas más, pero Marqués de Careaga, cuando hay que recordar, prefiere nombres que puede vincular de algún modo con

47. Gutierre Marqués de Careaga, "La poesía defendida, y difinida, Montalbán alabado», en Lágrimas panegíricas a la tenprana muerte del gran poeta i teólogo insigne doctor Juan Pérez de Montalbán, Madrid: Imprenta del Reino, 1639. Se suele encontrar al final de la obra y con otros discursos similares que también llevan numeración independiente, sin embargo falta en muchos ejemplares, así en la BNE solo lo encontramos en R-30.820, en cuyos ff. v.-9r. (cap. IX) trata las escritoras; a esa edición remiten las citas que seguirán.

48. No alude a sus dos hijas carmelitas, Cecilia del Nacimiento y María de San Alberto, que tienen una interesante poesía religiosa, por desgracia desatendida. 
su presente: Beatriz Galindo como ascendiente de «cavalleros muy nobles en esta corte»; Cecilia Morillas como madre de Francisco Sobrino, obispo de Valladolid; y Luisa Sigea por haber sido elogiada por Tomás Tamayo de Vargas, "coronista de la magestad católica y del nuevo mundo, cavallero novilíssimo de aquella imperial ciudad... y cuya noblesa da nuevo lustre a mi sangre, por lo que tiene de suya».

Aún queda por revisar un último espacio textual, el creado por algunas mujeres en sus propias obras. Las escritoras nunca ocuparon un lugar de poder en la sociedad cultural, de modo que el juicio sobre el canon, la jerarquía en el Parnaso, no pasó jamás por sus manos: ni tomaron parte en academias, ni fueron jueces de certámenes, ni actuaron como antólogas ni escribieron textos normativos de ningún tipo. No obstante, para explicar su propia posición autorial en ocasiones recurrieron a la cita de modelos autorizados femeninos como recurso argumentativo, lo que las obligó a establecer una selección canónica para construir su propio linaje intelectual. El más famoso y estudiado de estos discursos es, sin duda, el de sor Juana Inés de la Cruz, en su Respuesta a Sor Filotea, pero hay alguno anterior como la Carta ejecutoria de Feliciana Enríquez de Guzmán, contenida en la Tragicomedia de los jardines y campos sabeos (1624), el prólogo de Ana de Leiva en el Panigírico en alabanza de... Francisco de Este y el discurso de Filis en el desengaño cuarto de los Desengaños amorosos de María de Zayas (1647). Enríquez de Guzmán se siente cómoda tomando todos sus datos de una fuente latina muy autorizada como García Matamoros ${ }^{49}$, señal de su vocación por una cultura de raíz clásica y elitista, pero seguramente también de una conciencia de distinción respecto a otras escritoras de su tiempo. Cita a la marquesa del Cenete, Isabella Joya, Luisa Sigea, Ángela Zapata, Ana de Osorio y Catalina Paz, es decir, escritoras anteriores a su tiempo, cuya obra ella no pudo conocer; pero sobre todo silencia a coetáneas como Valentina Pinelo, cuya Vida de santa Ana se había impreso en Sevilla en 1604, lo que ella seguro sabía ${ }^{50}$. Sin apartarse del patrón clásico atemporal, Ana de Leyva, con idéntica necesidad de buscar una genealogía prestigiosa y moralmente

49. Ed. de Teresa Scott Soufas, en Women's Acts. Plays by Women Dramatists of Spain's Golden Age, Lexington: University of Kentucky Press, 1997, pp. 268-270, en p. 269; y en los Apuntes para una biblioteca..., ob. cit., I, pp. 385-387.

50. Es muy posible que también conociera la publicación de Magdalena de San Jerónimo, porque su obra social y penitenciaria con las mujeres descarriadas tuvo una amplísima repercusión en la España de su tiempo, en parte a través de su libro Razón y forma de la galera y casa real, Valladolid, 1608 y otras ediciones; vid, I. Barbeito, Cárceles y mujeres en el siglo XVII, Madrid; Castalia/Instituto de la Mujer, 1991. 
intachable, se mira en el espejo de la emperatriz Eudochia, Proba, Falconia, etc. ${ }^{51}$. María de Zayas, por el contrario, solo atiende a sus coetáneas rigurosas, entre las que selecciona damas de alcurnia que no pueden ser consideradas escritoras (Isabel Clara Eugenia, la condesa de Lemos), una hidalga (Isabel de Rivadeneyra, dama de la condesa de Galve), monjas (Eugenia de Contreras, María Barahona) o un nombre tan prestigioso y profesional como el de Ana Caro: nobleza, virtud y estatus profesional son los rasgos que Zayas, bajo la máscara de Filis, elige para identificarse como escritora ${ }^{52}$.

\section{UNA GOLONDRINA NO HACE VERANO}

El canon, el parnaso, se basa sobre el consenso, por lo que debe haber acuerdo en cuanto a ciertos nombres que se valoran como selectos y superiores a los demás. Tal como hemos visto, las escritoras no tienen apenas presencia en las listas o lugares que pretenden construir el parnaso hispano del Siglo de Oro, al menos no en las antologías más selectas ni en los comentarios de los autores más prestigiosos, que repetidos una y otra vez llegan a crear el consenso. En general, para encontrar citadas escritoras es más sencillo recurrir a los gineceos o galerías de mujeres ilustres, que están presentes no solo en obras ad hoc para la educación moral de las mujeres, sino en obras de erudición destinadas a estudiosos o cultos, a través de las cuales alcanzan una presencia constante en el imaginario escrito y pasan a formar parte de la tópica del tema cuando se trata de hacer una presentación positiva de la mujer. Estas listas testimonian cómo estos catálogos extensos de mujeres se construyen sobre varias fuentes, la mayoría de las veces siguiéndolas al pie de la letra y sin identificarlas, de modo que cuando se produce un error, se transmite sin mayor comprobación. Asimismo se observa que las categorías son en gran medida intercambiables, puesto que una misma mujer puede ser modelo de valor, castidad, piedad... o sabiduría, lo que convierte al conjunto

51. Ed. de Madrid: Imprenta del Reyno, 1638, h. 2r.

52. Partesegunda del sarao yentretenimiento honesto (1649), ed. de A. Yllera, Madrid: Cátedra, 1983, pp. 229-231. Por mantener la coherencia de este ensayo en sus límites geográficos peninsulares, omito referirme con detalle a la lista de sor Juana Inés de la Cruz en la Respuesta a sor Filotea. Se trata de un tema bien analizado por Carmen Peraíta, «Elocuencia y fama: el catálogo de mujeres sabias en la Respuesta de Sor Juana Inés», Bulletin of Hispanic Studies, LXXVII (2000), pp. 73-92; "La gran turba de las que merecieron nombres: Sor Juana’s Foremothers in La respuesta a Sor Filotea», en Coded Encounteres: Writing, Gender and Ethicity in Colonial Latin American, ed. de F. J. Ceballos Cardou et al., Amherst: University of Mass. Press, 1994, pp. 206-223. 
en un amontonamiento de nombres femeninos entre los que es imposible establecer una jerarquía, como la que exige el Parnaso.

Por otra parte, el hecho de incluirlas en estos gineceos y listas privativas, las constituye en una categoría marcada como femenino que no entra en contacto (no digamos ya en comparación) con el elenco masculino, este sí selecto y universal. Se trata de una segregación que permite elogiar los elementos de la serie, ponderar sus cualidades y valores, pero implícitamente restringirlos al círculo de exclusión en que quedan selladas y desde donde no compiten con la serie masculina. La modalidad más evidente de este procedimiento la encontramos en las obras que pretenden la exhaustividad y en las que las mujeres se agrupan bajo la única categoría de género.

Una función similar tiene la cita de antigüedad. Como los autores clásicos, que no compiten con los modernos, tampoco las vaguedades sobre nobles y sabias matronas griegas y romanas ofrecen algo más que un halo de perfección perdida con la práctica de virtudes heroicas en grado extremo. Las citas de Probas o Falconias ni plantean problemas en la jerarquización canónica ni a las escritoras del Siglo de Oro les sirven como modelo, puesto que su existencia solo es posible en mundos ideales ajenos a la esfera de la realidad social o literaria en que se mueven las coetáneas de nuestros panegiristas. $\mathrm{Su}$ presencia nominativa en estas obras suele formar parte de una propuesta ética y comportamental para la dama, en la que nunca tiene cabida la creación literaria (a veces ni siquiera la escritura) y llegado el caso hasta pueden ser empleadas para descalificar tales conductas impropias.

Sin embargo, tampoco es infrecuente que sin ningún límite cronológico se agrupe a la esposa de Lucano con Luisa Sigea o Sor Juana Inés de la Cruz, llegado el caso, como si todas ellas formaran parte de un mismo conjunto, cuyo rasgo común es 'mujeres sabias' (por ende excepcionales) sin que a esta categoría sea necesario añadir ninguna otra característica específica que las distinga entre sí. No digamos ya una posible categorización en diversas tendencias artísticas, estilos literarios, épocas o géneros, que necesitaría basarse en la consulta de la obra concreta sobre la que no se tienen datos, porque -salvo raras excepciones- la cita no se basa en un conocimiento real de los textos, que no son fácilmente asequibles a eruditos ni mucho menos a sus lectores, en caso de que quisieran acercarse directamente a las autoras elogiadas.

A la par de los gineceos, discurren las nóminas de escritores, que si inicialmente miran al mundo clásico, pronto acuden sólo a su entorno cronológico y lingüístico. Desde finales del siglo XVI y no antes empiezan a aparecer citadas algunas mujeres del entorno del autor de la lista parnasiana, que son incluidas entre los escritores y ponderadas como sabias o 
componedoras de versos. Lo primero que llama la atención es que el número de autoras citadas se multiplica frente a ese canon esclerotizado de sabias eruditas y que apenas coincide con él, ya que el peso de la actualidad, de las relaciones más inmediatas de quien construye la propuesta de Parnaso se impone en cada selección, dando lugar a una gran profusión de nombres. Tanto así que el otro rasgo caracterizador es la variación extrema entre las citadas en unas y otras nóminas, que no solo se basan en criterios de selección geográfica (por lo general de proximidad), sino en factores de peso social, conveniencia, moda e incluso época vital, puesto que la lista puede variar a lo largo de la existencia de un autor. Este hecho demuestra la carencia de un mínimo parnaso femenino en el siglo XVII con algunos nombres reconocibles sobre los que se hubiera creado un consenso, pero más allá es síntoma de la falta de credibilidad que para los mismos autores tuvieron las selecciones de otros poetas, puesto que en ningún caso se observa la transmisión de datos entre unas y otras, como si entre los autores de parnasos existiera la asunción tácita de que cada selección, en el caso de las mujeres, tenía un carácter coyuntural y personal que la convertía en única e intransferible, frente a un canon masculino de bases reconocibles y compartidas. No supieron tampoco superar este escollo las propias autoras, que en las contadísimas ocasiones en que trazan su genealogía creativa actúan también bajo el signo de la dispersión.

De hecho, es más que llamativo que no sean las autoras de obra impresa las preferentemente citadas. Beatriz Bernal, Valentina Pinelo, Isabel de Liaño, Feliciana Enríquez de Guzmán, María Nieto de Aragón o Laura Mauricia (seudónimo de Leonor de Meneses) no figuran en estas listas de sabiduría, aunque sus obras llegaron a pasar a las prensas, desmintiendo en cierto sentido la afirmación de María de Zayas de que los escritos no tienen valor cierto hasta que se rozan en las letras de plomo. Ana de Castro Egas, que en 1629 publicaba su Eternidad de Felipe III en cuyo prólogo participó un gran número de autores de la corte (Lope y Quevedo, entre otros), fue luego totalmente ignorada en los parnasos; Santa Teresa es la autora más leída del Siglo de Oro, por delante de muchos autores, lo mismo que María de Zayas, sucesivamente reeditada, sin embargo tampoco obtienen un puesto más alto en el ránkin. Ciertamente sus obras se mencionan en los compendios bibliográficos a la par que las de los autores, entremezcladas con ellos, pero precisamente ahí, donde parecen quedar equiparadas, es donde pasan desapercibidas y son igualmente olvidadas.

El Siglo de Oro, a partir de 1600, conoció la existencia de un nutrido grupo de escritoras que se afanaron por darse a conocer, por publicar, por participar en actos públicos. Su presencia fue apenas acusada entre los 
escritores, que a través de la dispersión en la cita impidieron la formación de un grupo definido de nombres, lo que dejó la selección en manos de los eruditos, más proclives a hurgar en la antigüedad y el halo de saber a través del acarreo de fuentes de autoridad que a hacer una relación fundamentada en datos históricos fehacientes, comprobables y actualizados. Así, cuando se inicia a finales del siglo XVIII la historia de nuestra literatura, en el caso de las escritoras carece de cualesquiera claves interpretativas y debe operar sobre los listados de erudición a la par que sobre datos concretos de obras para los cuales apenas existen juicios previos. Este vacío se solventa a través de la acumulación de citas parcialmente indiscriminadas y de nombres asignados a grandes períodos cronológicos, convirtiendo los doscientos años entre 1500 y 1700 en una etapa única. De hecho, la situación actual es en gran medida heredera directa de ese pasado crítico, porque es verdad que conocemos bastantes autoras, hay ediciones abundantes, facsímiles, repertorios e incluso algunas obras son reiteradamente estudiadas desde posturas críticas diversas, pero fuera de dos o tres autoras, aún seguimos sin acordar un canon, sin establecer una historia meditada, rigurosa o estructurada, sin ver un diseño que permita trazar la orografía de un parnaso femenino. 